\title{
Effect of Infused Ketone Bodies on Glucose Utilization in the Dog*
}

\author{
P. W. Felts, $\dagger$ O. B. Crofford, $\$$ and C. R. Park \\ (From the Departments of Medicine and Physiology, Vanderbilt University, Nashville, Tenn.)
}

Williamson and Krebs (1) and Hall (2) have shown that acetoacetate and $\beta$-hydroxybutyrate inhibit the uptake and oxidation of glucose in the isolated, perfused rat heart. This effect is observed both in the presence (1) and in the absence (2) of insulin. Long-chain fatty acids also impair glucose utilization as shown by Shipp, Opie, and Challoner (3), Bowman (4), and Minton and Raben (5). A similar inhibition of glucose uptake by ketone bodies and fatty acids has been observed by using the isolated rat diaphragm. The mechanism of this effect has been studied by Newsholme and associates $(6,7)$. They have shown that fatty acids reduce the sensitivity of glucose transport in muscle to the accelerating effect of insulin (7) and impair the intracellular phosphorylation of glucose by inhibition of the phosphof ructokinase reaction (6).

On the basis of these in vitro studies, Randle, Garland, Hales, and Newsholme (7) have recently advanced a general proposal that a rise in plasma fatty acids and ketone bodies may impair glucose utilization in the whole animal under certain conditions. On a clinical level, such an effect might relate to the diminished glucose utilization associated with diabetic ketoacidosis, and the glucose intolerance observed in Cushing's syndrome, acromegaly, and starvation. In these conditions, improvement in glucose tolerance coincides with a reduction in blood lipids and ketones $(8)$.

In apparent contradiction to the proposal of

* Submitted for publication June 12, 1963; accepted November 29, 1963.

Supported in part by U. S. Public Health Service grant AM-04361-03.

$\dagger$ Fellow of the Life Insurance Medical Research Fund. Present address: II Medizinische Klinik, der Universität München, Ziemssenstrasse, Munich, Germany.

$\$$ Present address: Institut de Biochimie Clinique, Université de Genève, Sentier de la Roseraie, Geneva, Switzerland.
Randle and co-workers ( 7$)$, the infusion of ketone bodies into the normal, fasting dog induces hypoglycemia (9). Recent studies suggest that this effect is due to a reduction in hepatic glucose output as a consequence of increased insulin secretion $(10-12)$.

In the present study, we have re-examined the effect of ketone body infusion in the intact dog with the view that either hyperglycemia or hypoglycemia might be induced, depending on the particular experimental conditions. According to the in vitro studies cited above, inhibition of glucose utilization by ketone bodies should be most readily demonstrable when the rate of glucose utilization in the peripheral tissues is elevated. A rapid utilization could be induced experimentally by a sustained infusion of glucose that raises the plasma concentration and stimulates release of endogenous insulin. Ketone bodies infused under these conditions had a hyperglycemic effect. On the other hand, when ketone bodies were infused into the normoglycemic dog, hypoglycemia was observed. The relationship of these observations to certain clinical syndromes is discussed.

\section{Methods}

Female mongrel dogs, weighing 9 to $16 \mathrm{~kg}$, were housed in individual cages and fed Purina dog chow ad libitum for approximately 1 week before study. At least 7 days elapsed between experiments performed in the same dog. After 12 to 18 hours of fasting with free access to water, each dog was lightly anesthetized with an initial iv dose of sodium pentobarbital, $27 \mathrm{mg}$ per $\mathrm{kg}$, and maintained with supplemental doses as needed. Intermittent blood samples were withdrawn through a no. 18 gauge indwelling femoral arterial needle into heparinized syringes. All samples were promptly iced and the plasmas separated by centrifugation at $4^{\circ} \mathrm{C}$.

Continuous monitoring of the glucose concentration of mixed venous blood was obtained with an autoanalyzer (13). ${ }^{1}$ As used in these experiments, there was a readout delay of 7 minutes. A small double lumen catheter

\footnotetext{
1 Technicon Instruments, Inc., Chauncey, N. Y.
} 
(polyethylene tubing, 0.011 i.d. $\times 0.024$ o.d. within polyethylene tubing 0.030 i.d. $\times 0.048$ o.d.) was inserted percutaneously through a no. 16 gauge, thin-wall needle into the left external jugular vein and advanced to the level of the right atrium. With the autoanalyzer's peristaltic manifold pump, heparinized saline (20 U sodium heparin per $\mathrm{ml}, 0.9 \% \mathrm{NaCl}$ ) was infused through the outer lumen at $0.6 \mathrm{ml}$ per minute and the heparin-blood mixture withdrawn through the inner lumen at $0.8 \mathrm{ml}$ per minute. The concentration of reducing substances present in a dialyzate of the heparinized blood was taken as the measure of blood glucose concentration (14). Standardization was accomplished for each experiment by sampling glucose solutions of known concentration before and after the procedure. Glucose determinations on arterial blood samples were performed by the glucose oxidase method of Huggett and Nixon (15). Values by the two methods agreed closely.

To elevate and maintain blood sugar concentrations at or around $180 \mathrm{mg}$ per $100 \mathrm{ml}$, glucose was administered into either femoral vein from a $200-\mathrm{ml}$ mechanically driven syringe. ${ }^{2}$ The priming dose of glucose $(200 \mathrm{mg}$ per $\mathrm{kg}$ over 30 seconds) was followed by a constant infusion of $6.4 \mathrm{mg}$ per $\mathrm{kg}$ per minute. After a steady glucose equilibrium concentration was reached (usually in 30 to 60 minutes), either acetoacetate or $\beta$-hydroxybutyrate was administered into the other femoral vein by a similar syringe. This syringe was cooled to $4^{\circ} \mathrm{C}$ by a polyethylene coil containing circulating ice water to retard the nonenzymic decarboxylation of acetoacetate. Aceto-

- Harvard Apparatus Company, Inc., Dover, Mass. acetate, prepared in $1.0 \mathrm{M}$ solution by hydrolysis of redistilled ethyl acetoacetate (16), was given in a priming dose of $0.25 \mathrm{~g}$ per $\mathrm{kg}$ followed by a constant infusion of $8.3 \mathrm{mg}$ per $\mathrm{kg}$ per minute. The racemic mixture of $\mathrm{D}, \mathrm{L}-\boldsymbol{\beta}$-hydroxybutyrate ${ }^{3}$ was infused at a rate approximately twice that of acetoacetate (primer, $0.5 \mathrm{~g}$ per $\mathrm{kg}$, and constant infusion, $12.5 \mathrm{mg}$ per $\mathrm{kg}$ per minute at about $0.8 \mathrm{M}$ ).

Plasma ketone body concentrations were routinely determined in barium-zinc filtrates (17) as described by Chernick (18). On occasion, the simplified micromethod of Pawan (19) was used to measure acetoacetate only. $\mathrm{D}(-)-\beta$-Hydroxybutyrate was assayed enzymatically on the same filtrates with a partially purified enzyme preparation isolated from Rhodopseudomonas spheroides ${ }^{4}$ as described by Williamson, Mellanby, and Krebs (20).

Biopsy of quadratus femoris muscle of one side was performed just before the ketone body infusion, and the contralateral muscle was biopsied 60 minutes after the infusion was underway. A 4- to 5-g muscle segment was rapidly excised and frozen with a Wollenberger clamp (21) cooled in liquid nitrogen. Estimates of the glucose space and hexose phosphate concentrations were carried out enzymatically as described by Regen, Morgan, and Park (22). Chloride space was determined by a microadaptation of the method of Sanderson (23).

${ }^{3}$ Sodium salt. Sigma Laboratories, St. Louis, Mo., or Mann Research Laboratory, New York, N. Y.

4 Strain 8253, American Type Culture Collection, Washington, D. C.

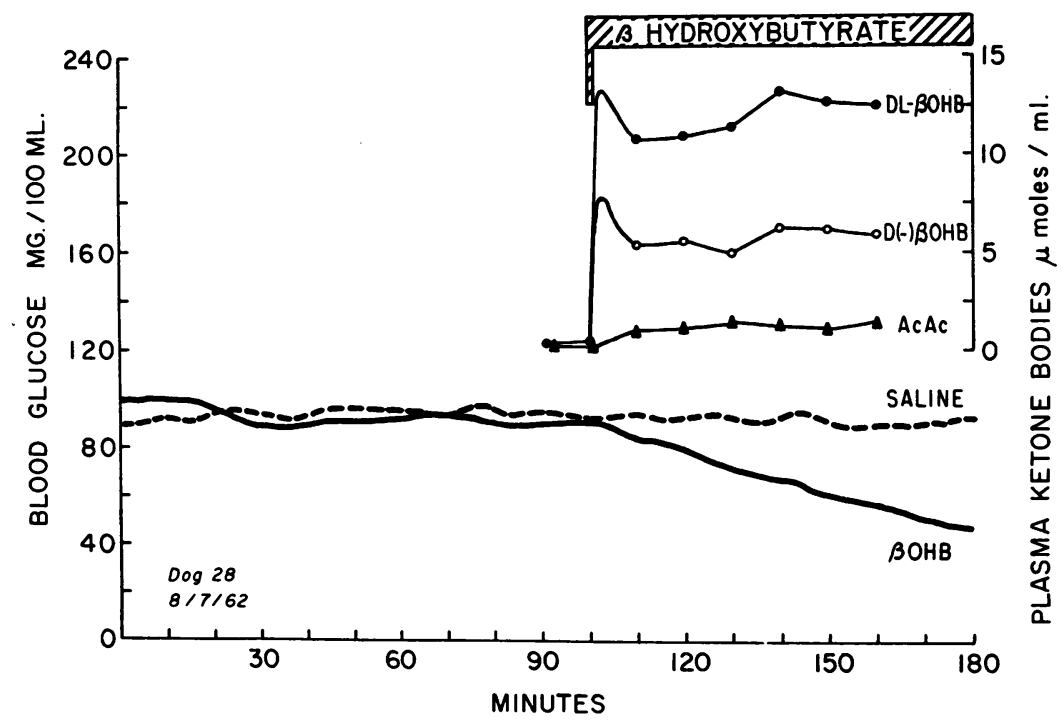

Fig. 1. Hypoglycemia with $\beta$-HydRoXybutyrate infUSion IN THE FASTiNG DOG (solid lines) CONTRASTED TO THE BLOOD SUGAR THROUGHOUT CONTROL SALINE INFUSION (broken line). Plasma D,L- $\beta$-hydroxybutyrate, $\bullet$, and acetone plus acetoacetate, $\boldsymbol{\Delta}$, by chemical determination; $\mathrm{D}(-)-\beta$-hydroxybutyrate, $O$, enzymatically. 
P. W. FELTS, O. B. CROFFORD, AND C. R. PARK

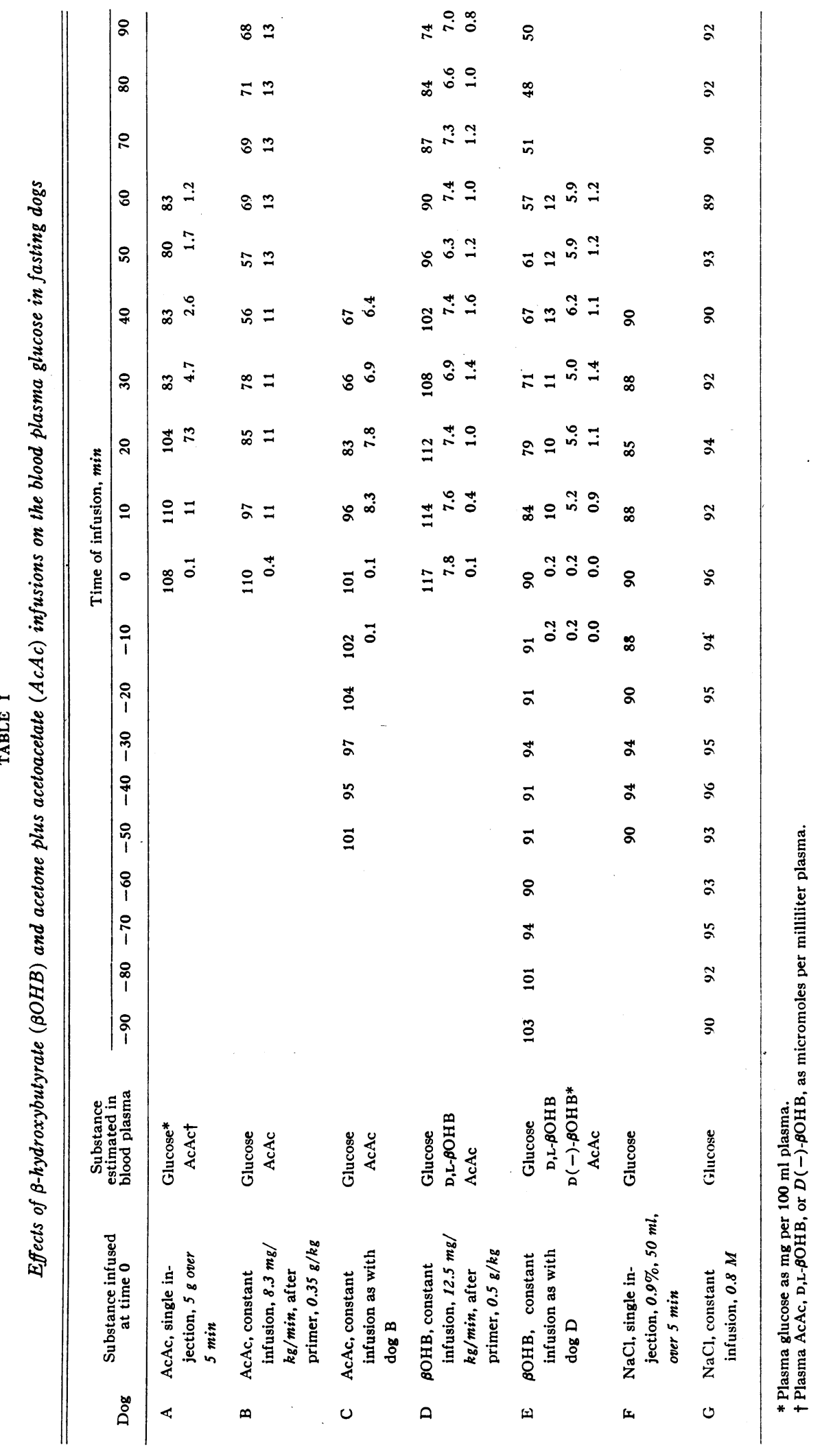




\section{Results}

Hypoglycemia after ketone body infusion in the fasting dog. As noted in Figure 1, the blood glucose of the normal fasting dog was constant throughout the period of observation (180 minutes) and was unaffected by the infusion of hypertonic saline of the same molarity as the ketone body infusions later employed. IVhen sodium chloride was replaced by either acetoacetate or $\beta$-hydroxybutyrate, hypoglycemia promptly en- sued, in agreement with previous observations (9-11). Acetoacetate was administered in buffered solution, and no significant change occurred in the blood $\mathrm{pH}$. Table I summarizes the effects in seven dogs of infusion of acetoacetate, $\beta$-hydroxybutyrate, or $\mathrm{NaCl}$ on the blood plasma glucose and ketone body levels.

Improved glucose tolerance during ketone bodyinduced hypoglycemia. When these same experiments were repeated, but with the addition of a single intravenous injection of glucose $30 \mathrm{~min}$ -
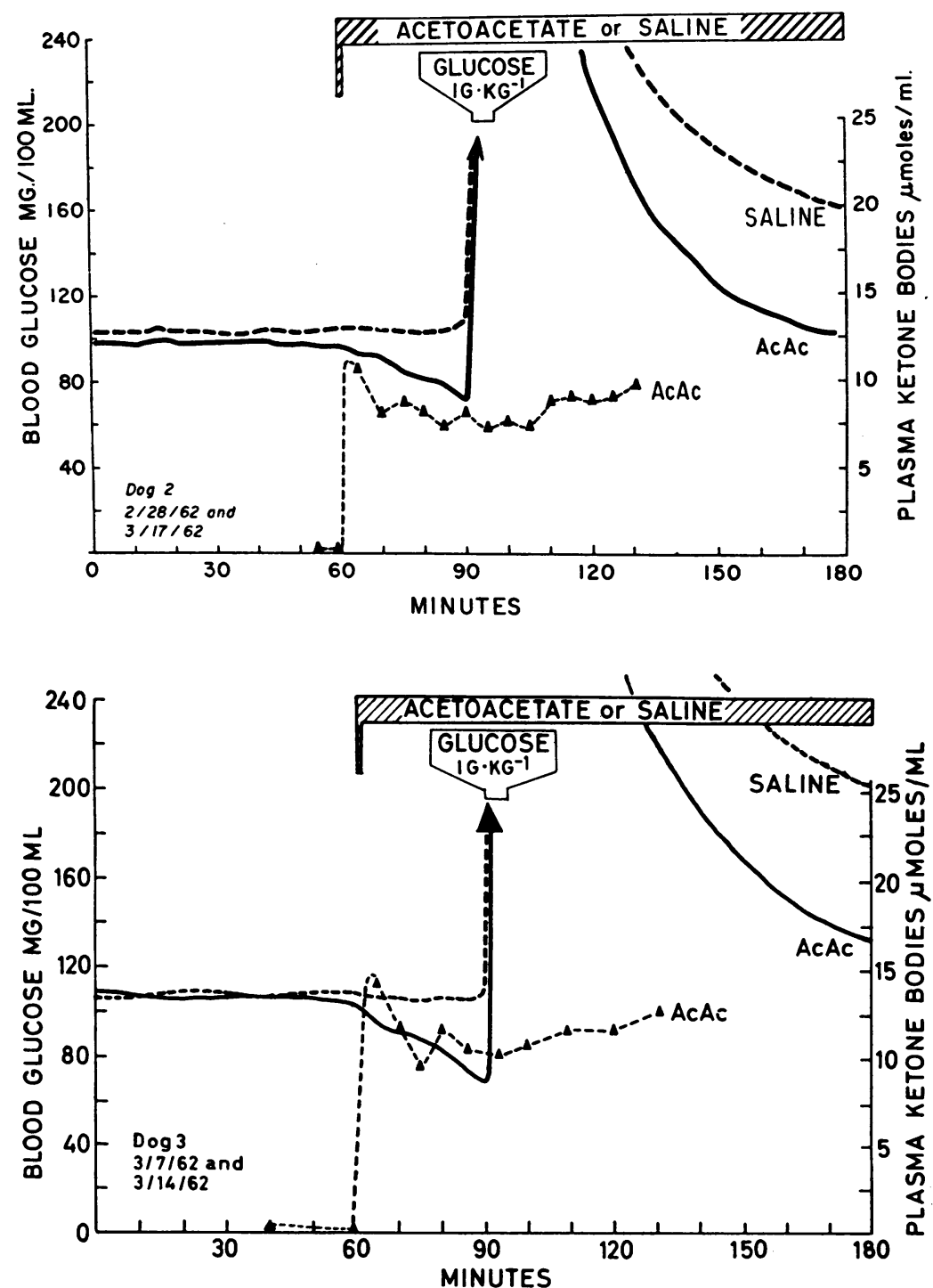

Fig. 2. Improved GLUCOSE tOLERANCE AFTER Single INJeCtion OF GLUCOSE DURING ACETOACETATE-INDUCED HYPOGLYCEMIA (solid lines) CONTRASTED TO THAT DURING SALINE INFUSION (broken line) IN THE SAME DOG. Two experiments are illustrated. Plasma acetoacetate, $\boldsymbol{\Delta}$. 


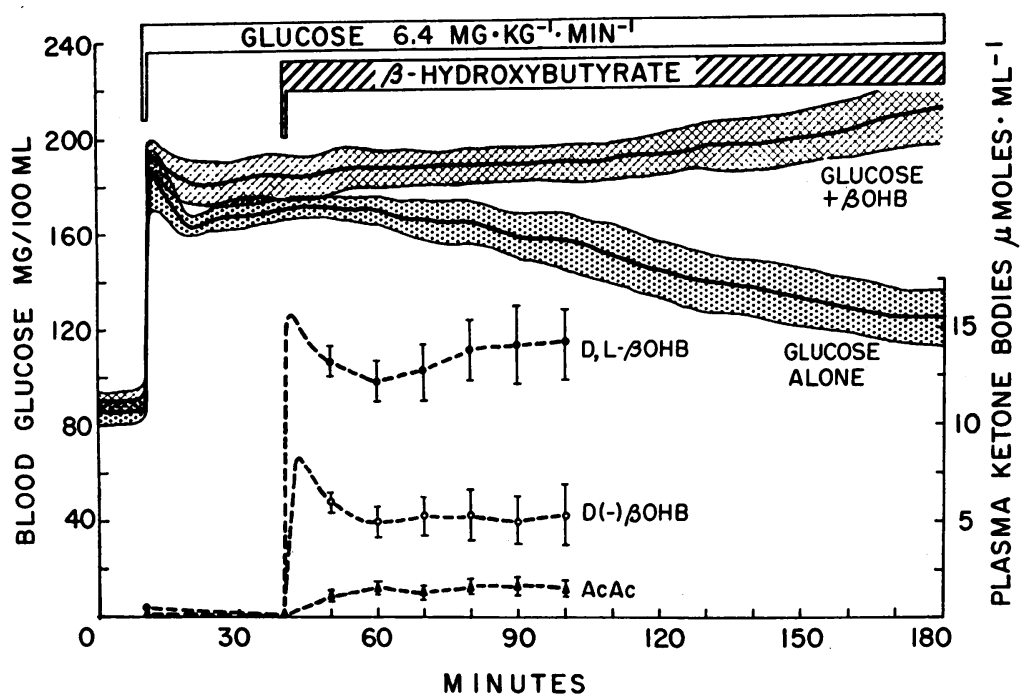

Fig. 3. EFFECT OF $\beta$-HYDROXYBUTYRATE INFUSIONS ON BLOOD GLUCOSE LEVELS DURING HYPERGLYCEMIA DUE TO CONTINUOUS GLUCOSE INFUSION. The blood glucose concentrations are presented as the mean of four experiments \pm SE. Plasma $D, L-\beta$-hydroxybutyrate, $\bigcirc ; \mathrm{D}(-)$ - $\beta$-hydroxybutyrate, $\mathrm{O}$; and acetone plus acetoacetate, $\boldsymbol{\Delta}$

utes after initiating the ketone body infusion, obvious improvement of glucose tolerance resulted. Figure 2 shows curves obtained in the same dog in response to identical glucose loads, one during acetoacetate infusion and the other during saline infusion. Initial hypoglycemia from the ketone infusion is again apparent as well as the improvement in the glucose tolerance. Two examples are shown.

Adaptive responses of the blood sugar to continuous glucose infusions. An appreciation of the behavior of the blood sugar during a continu-

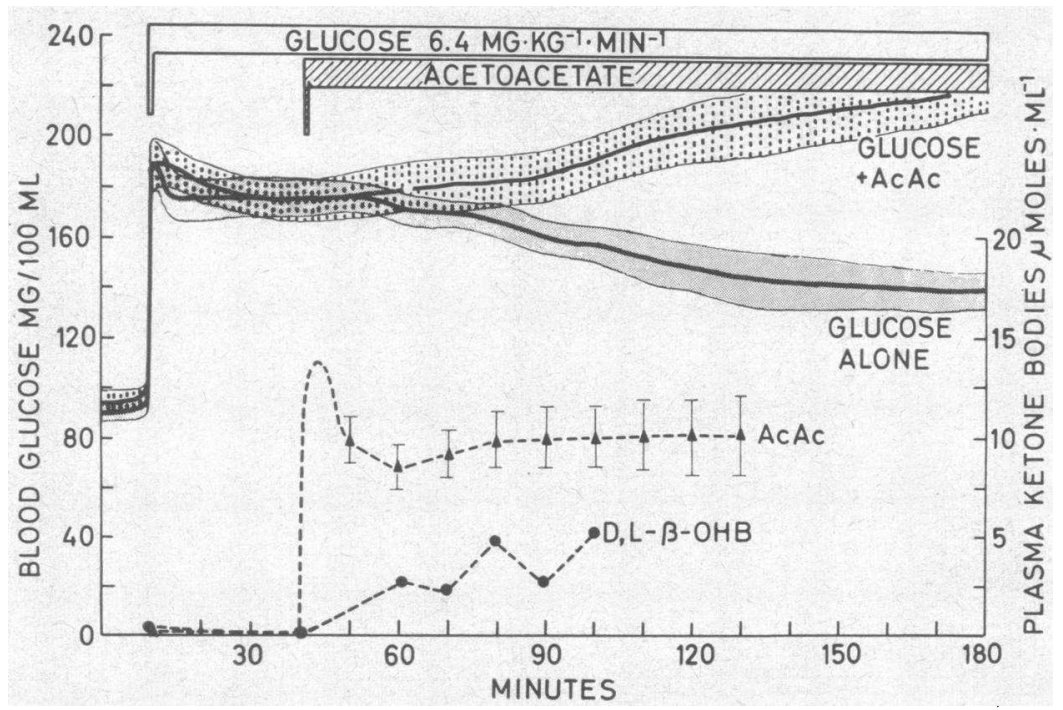

Fig. 4. EFfect of ACETOACETATE infusions on BLOOD GLUCOSE LEVELS DURING HYPERGLYCEMIA DUE TO CONTINUOUS GLUCOSE INFUSION. The control curve is the mean $\pm \mathrm{SE}$ of seven experiments, whereas the AcAc curve represents four experiments. Plasma acetoacetate plus acetone, $\boldsymbol{\Delta} ; \mathrm{D}, \mathrm{L}-\boldsymbol{\beta}$-hydroxybutyrate, 
ous infusion of glucose is essential to the interpretation of subsequent data. The priming dose of glucose resulted in a peak blood sugar concentration approximately $100 \mathrm{mg}$ per $100 \mathrm{ml}$ above the fasting value. Disappearance of primer was retarded by the constant infusion, and a glucose steady-state concentration of about 160 to $180 \mathrm{mg}$ per $100 \mathrm{ml}$ was approached in 30 to 60 minutes. This steady state was usually maintained for only 15 to 20 minutes, and then a gradual fall in blood glucose concentration ensued. In none of the dogs did the blood glucose level rise or even remain constant for more than 30 minutes after the equilibrium concentration was reached.

Diabetogenic effect of ketone bodies infused into the hyperglycemic dog. In contrast to the response to glucose alone, infusions of ketone bodies, begun during the plateau period, prevented the fall in blood sugar. Figure 3 is a summary of four control glucose infusions and four with glucose and $\beta$-hydroxybutyrate, whereas Figure 4 shows seven control and four with acetoacetate. The blood glucose concentrations are graphically presented as the mean $\pm 1 \mathrm{SE}$. When glucose alone was infused, the adaptive fall in the blood sugar continued throughout the period of observation. When the ketone infusion was begun during the equilibrium period, a gradual rise in the blood sugar concentration occurred. In the majority of animals, retardation in the glucose disappearance rate became manifest within 15 to 30 minutes after beginning the ketone body infusion as a progressive rise in blood glucose that continued throughout the period of observation. In the remainder, the ketone body infusion simply maintained the blood glucose at a constant level. The plasma ketone body levels are also shown as the mean $\pm 1 \mathrm{SE}$. A rise in the plasma acetoacetate concentration accompanied the infusion of $\beta$-hydroxybutyrate, and similarly, an increase in $\beta$-hydroxybutyrate occurred with acetoacetate infusions. In all cases, the plasma concentration of the infused ketone body reached levels in excess of $5 \mu$ moles per ml.

Intracellular glucose and hexose phosphate analyses. Quick frozen skeletal muscle specimens, obtained before and 60 minutes after initiating the ketone body infusion, were assayed enzymatically for glucose and hexose phosphates. Chloride space was used as an estimate of extra-
TABLE II

\begin{tabular}{|c|c|c|}
\hline & $\begin{array}{r}\text { Preinfusion } \\
\text { Mean }\end{array}$ & $\begin{aligned} & \text { Postinfusion } \\
\pm & \mathrm{SE}\end{aligned}$ \\
\hline $\begin{array}{l}\text { Glucose space, } \\
\text { ml/g wet wt }\end{array}$ & $0.16 \pm 0.02$ & $0.15 \pm 0.02$ \\
\hline $\begin{array}{l}\text { Chloride space, } \\
m l / g \text { wet wt }\end{array}$ & $0.14 \pm 0.03$ & $0.13 \pm 0.06$ \\
\hline $\begin{array}{l}\text { Glucose-6-phosphate, } \\
\text { rmoles/g dry wt }\end{array}$ & $0.65 \pm 0.19$ & $0.55 \pm 0.15$ \\
\hline $\begin{array}{l}\text { Fructose-6-phosphate, } \\
\text { нmoles /g dry wt }\end{array}$ & $0.08 \pm 0.02$ & $0.11 \pm 0.03$ \\
\hline $\begin{array}{l}\text { Fructose-1,6-diphosphate, } \\
\text { нmoles } / g d r y \text { wt }\end{array}$ & $0.06 \pm 0.02$ & $0.04 \pm 0.01$ \\
\hline
\end{tabular}

* The values are the means of eight determinations.

cellular water. Since the glucose space did not exceed the extracellular space significantly, the infusion of ketone bodies did not cause any measurable accumulation of intracellular free glucose. As seen in Table II, there were no significant changes in the hexose phosphates during the period of ketone body infusion.

\section{Discussion}

Previously described effects of ketone body infusions on blood glucose may be grouped in three categories. 1) Hyperglycemia after $\beta$-hydroxybutyrate was described by Mirsky and Broh-Kahn (24) in 1937 in nephrectomized rabbits, and similarly Caccuri in 1937, using rabbits (25), and Seltzer in 1962, using dogs (26), observed hyperglycemia after acetone infusions. Drury and Wick (27) showed a reduction in glucose oxidation in eviscerated rabbits after ketone body infusion without any decrease in glucose disappearance from the blood stream. 2) No effect upon the blood sugar was noted by Koehler, Windsor, and Hill (28) with acetone and acetoacetate administration to humans or by Seltzer (26) with $\beta$-hydroxybutyrate in dogs. 3) Hypoglycemia has been observed by Nath and Brahmachari (29) as the initial response to injection of acetoacetate or $\beta$-hydroxybutyrate in guinea pigs and rabbits. This was associated with increased plasma insulin-like activity and pancreatic extractable insulin. Continued daily injections of ketone bodies led to the gradual development of hyper- 
glycemia with decreased insulin in the blood and pancreas by day 70 . These authors suggested that ketone bodies first stimulate insulin secretion with gradual exhaustion of islet cells supervening (2933). Tidwell and Axelrod (34) also suggested that acetoacetate stimulates insulin release in the rat.

In fasting dogs given $\beta$-hydroxybutyrate, Neptune (9) observed a consistent drop in blood sugar. Madison and his associates (10-11), using dogs with chronic portacaval shunts, have provided further evidence for the prompt hypoglycemic effect of either acetoacetate or $\beta$-hydroxybutyrate. They found an increased insulin content in pancreatic venous blood and attributed the hypoglycemia to a diminution of hepatic glucose output. Our findings in the normoglycemic dog (Figure 1 and Table I) are consistent with these studies. The improvement of glucose tolerance during ketone body-induced hypoglycemia (Figure 2) would be expected with higher levels of circulating insulin.

In the presence of sustained hyperglycemia, on the other hand, ketone bodies tend to raise the blood sugar concentration (Figures 3 and 4). This effect is most simply interpreted as follows. Elevation of blood glucose is the optimal physiologic stimulus to the pancreatic $\beta$-cells and raises insulin secretion to a level where no further response can be obtained from ketone bodies. The combination of hyperglycemia and elevated insulin arrests hepatic glucose output (12) and establishes a high rate of peripheral glucose uptake. Under these conditions, the inhibitory effect of ketone bodies on peripheral uptake becomes manifest by a rise in the blood glucose or an arrest of its normal tendency to fall. This interpretation is consistent with the demonstrated in vitro effects of ketone bodies on glucose utilization, but is obviously not established by the present data from the whole animal without estimates of glucose production and uptake rates.

Glucose uptake in the muscle biopsied in these experiments (Table II) was apparently limited by the membrane transport step, since no intracellular free glucose could be demonstrated (3536). Studies in rats (37) have also failed to show intracellular free glucose in resting skeletal muscle even when marked hyperglycemia has been induced with presumably maximal release of en- dogenous insulin. Under these conditions, the important inhibitory effect of ketone bodies presumably is exerted at the transport level where they reduce the sensitivity to insulin (7). With transport limiting the availability of substrate, an inhibition of glucose- or fructose-6-phosphate phosphorylation by the ketone bodies, unless extreme, would not be expected to cause any marked change in hexose phosphate concentrations.

Plasmas ketone body levels reached in these studies were well beyond the limits seen in diabetic ketoacidosis, and no attempt was made to determine the minimal effective concentration. The modest levels of plasma ketone bodies following an overnight fast may in themselves have some slight inhibitory effect upon peripheral glucose utilization. The release of such an inhibition could account for the progressive improvement of glucose utilization during the course of the control of glucose infusion (Figures 3 and 4). A gradual increase in insulin production is another factor which may be involved.

The present experiments provide some support for the idea that ketone bodies may be diabetogenic under certain conditions. In particular, syndromes characterized by increased glucose production (analogous to the continuous infusion of glucose) and increased fat mobilization and catabolism should be considered. These metabolic alterations are commonly observed in Cushing's syndrome, certain forms of acromegaly, and in diabetic ketoacidosis. These states are also characterized by insulin insensitivity as would be expected from the effect of fatty acids and ketone bodies in in vitro systems (7). The possibility is good that the elevated blood lipids also contribute to the glucose intolerance seen with fasting, as discussed by Randle and associates (7).

\section{Summary}

Ketone body infusion into the intact fasting dog produces prompt hypoglycemia and improves glucose tolerance: When hyperglycemia is established by the constant infusion of glucose, acetoacetate or $\beta$-hydroxybutyrate promotes hyperglycemia. This effect is consistent with an inhibition of peripheral glucose utilization, in accord with the findings of others using isolated 
muscle preparations. Such an inhibition of peripheral uptake may play a role in the faulty glucose utilization seen in certain clinical disorders in which increased fat mobilization occurs.

\section{References}

1. Williamson, J. R., and H. A. Krebs. Acetoacetate as fuel of respiration in the perfused rat heart. Biochem. J. 1961, 80, 540.

2. Hall, L. M. Preferential oxidation of acetoacetate by the perfused heart. Biochem. biophys. Res. Commun. 1961, 6, 177.

3. Shipp, J. C., L. H. Opie, and D. Challoner. Fatty acid and glucose metabolism in the perfused heart. Nature (Lond.) 1961, 189, 1018.

4. Bowman, R. H. The effect of long-chain fatty acids on glucose utilization in the isolated perfused rat heart. Biochem. J. 1962, 84, P. 14.

5. Minton, P. R., and M. S. Raben. Depression of glucose oxidation by palmitate and acetoacetate in the perfused rat heart (abstract). J. clin. Invest. 1962, 41, 1385.

6. Newsholme, E. A., P. J. Randle, and K. L. Manchester. Inhibition of the phosphofructokinase reaction in perfused rat heart by respiration of ketone bodies, fatty acids and pyruvate. Nature (Lond.) 1962, 193, 270.

7. Randle, P. J., P. B. Garland, C. N. Hales, and E. A. Newsholme. The glucose fatty-acid cycle. Its role in insulin sensitivity and the metabolic disturbances of diabetes mellitus. Lancet 1963, 1, 785.

8. Man, E. B., and M. J. Albrink. Serum lipids in different phases of carbohydrate metabolism. Yale J. Biol. Med. 1956-57, 29, 316.

9. Neptune, E. M., Jr. Changes in blood glucose during metabolism of $\beta$-hydroxybutyrate. Amer. J. Physiol. 1956, 187, 451.

10. Mebane, D., and L. Madison. The hypoglycemic effect of ketone bodies (abstract). J. clin. Invest. 1962, 41, 1383.

11. Madison, L., D. Mebane, R. Unger, and A. Lochner. Evidence for a stimulatory feedback of ketone acids on pancreatic beta cells. Clin. Res. Proc. 1963, 11, 63

12. Madison, L. L., D. Mebane, F. Lecocq, and B. Combes. Physiological significance of secretion of endogenous insulin into the portal circulation. V. Quantitative importance of the liver in the disposition of glucose loads. Diabetes 1963, 12, 8.

13. Weller, C., M. Linder, A. Macaulay, A. Ferrari, and G. Kessler. Continuous in vivo determination of blood glucose in human subjects. Ann. N. Y. Acad. Sci. 1960, 87, 658.

14. Technicon Autoanalyzer Methodology Manual. Chauncey, N. Y., Technicon Instruments.

15. Huggett, A. St. G., and D. A. Nixon. Use of glucose oxidase, peroxidase, and o-dianisidine in de- termination of blood and urinary glucose. Lancet 1957, 2, 368

16. Krebs, H. A., and L. V. Eggleston. Metabolism of acetoacetate in animal tissues. Biochem J. 1945, 39, 408.

17. Somogyi, M. Determination of blood sugar. J. biol. Chem. 1945, 160, 69.

18. Chernick, S. S. Production and measurement of ketone bodies in Measurement of Exocrine and Endocrine Functions of the Pancreas, F. W. Sunderman and F. W. Sunderman, Jr., Eds. Philadelphia, J. B. Lippincott, 1961, p. 147.

19. Pawan, G. L. S. A simple micromethod for the quantitative determination of acetone and acetoacetate in biological fluids. Biochem. J. 1958, 68, P. 33.

20. Williamson, D. H., J. Mellanby, and H. A. Krebs. Enzymic determination of $\mathrm{D}(-)-\boldsymbol{\beta}$-hydroxybutyric acid and acetoacetic acid in blood. Biochem. J. 1962, 82, 90.

21. Wollenberger, A., O. Ristau, and G. Schoffa. Eine einfache Technik der extrem schnellen Abkuhlung groberer Gewebestucke. Pflügers Arch ges. Physiol. 1960, 270, 399.

22. Regen, D. L., W. W. Davis, H. E. Morgan, and C. R. Park. The regulation of hexokinase and phosphofructokinase activity in heart muscle. Effects of alloxan diabetes, growth hormone, cortisol and anoxia. J. biol. Chem. 1964, 239, 43.

23. Sanderson, P. H. Potentiometric determination of chloride in biological fluids. Biochem. J. 1952, 52, 502 .

24. Mirsky, I. A., and R. H. Broh-Kahn. The influence of increased metabolism on $\beta$-hydroxybutyric acid utilization. Amer. J. Physiol. 1937, 120, 446.

25. Caccuri, S. Modificazioni della chetonemia nell' intossicazione sperimentale da acetone. Biochim. Terap. sper. 1937, 24, 169

26. Seltzer, H. S. Insulin secretion and insulin-activity during metabolic acidosis: relation to insulin resistance. Program Amer. Diabetes Ass. Chicago, June 1962.

27. Drury, D. R., and A. N. Wick. The effect of $\beta$-hydroxybutyric acid on glucose oxidation in insulinized animals. J. biol. Chem. 1952, 196, 129.

28. Koehler, A. E., E. Windsor, and E. Hill. Acetone and acetoacetic acid studies in man. J. biol. Chem. $1941,140,811$.

29. Nath, M. C., and H. D. Brahmachari. Experimental hyperglycaemia by injection of intermediary fat metabolism products in rabbits. Nature (Lond.) 1944, 154, 487.

30. Nath, M. C., and H. D. Brahmachari. Relation of intermediary metabolites to the lowering of the potency of pancreatic insulin in the animal system. Nature (Lond.) 1948, 161, 18.

31. Nath, M. C., and H. D. Brahmachari. Studies on the (æ) biological factors responsible for the onset of diabetic symptoms. I. Effect of prolonged injection of intermediary fat metabolites on the 
blood-sugar level in the normal animals. Indian J. med. Res. 1949, 37, 61.

32. Brahmachari, H. D., and M. Kumar. Effect of $\beta$-hydroxybutyrate injections on the pancreatic activity of guinea pigs. Nature (Lond.) 1959, 183, 51.

33. Brahmachari, H. D., and G. R. Sarma. Effects of injections of some intermediary metabolites on the "insulin response" of normal rabbits. Nature (Lond.) 1961, 191, 491.

34. Tidwell, H. C., and H. E. Axelrod. Blood sugar after injection of acetoacetate. J. biol. Chem. 1948, 172, 179.

35. Park, C. R. The effect of insulin and alloxan diabetes on the transport of glucose and other sugars into the cells of muscle and brain in The Hypophyseal Growth Hormone, Nature and Actions, R. W. Smith, Jr., O. H. Gaebler, and C. N. H. Long, Eds. New York, McGraw-Hill, 1955, p. 394.

36. Morgan, H. E., E. Cadenas, D. M. Regen, and C. R. Park. Regulation of glucose uptake in muscle. II. Rate-limiting steps and effects of insulin and anoxia in heart muscle from diabetic rats. J. biol. Chem. 1961, 236, 262.

37. Park, C. R., and L. H. Johnson. Effect of insulin on transport of glucose and galactose into cells of rat muscle and brain. Amer. J. Physiol. 1955, 182, 17. 